\title{
Preparation, thermal analysis, and crystal structure refinement of the quaternary alloy $(\mathrm{CuIn})_{2} \mathrm{NbTe}_{5}$
}

\author{
P. Grima-Gallardo ${ }^{a, b}$, M. Palmera ${ }^{b}$, J. A. Aitken ${ }^{c}$, J. Cisterna ${ }^{d}$, I. Brito ${ }^{d}$, and G. E. Delgado ${ }^{d, e, *}$ \\ ${ }^{a}$ Centro de Estudios de Semiconductores, Departamento de Física, Facultad de Ciencias, \\ Universidad de Los Andes, Mérida 5101, Venezuela. \\ ${ }^{b}$ Centro Nacional de Tecnologías Ópticas y \\ Centro de Investigaciones de Astronomía, Mérida 5101, Venezuela. \\ ${ }^{c}$ Department of Chemistry and Biochemistry, Duquesne University, \\ Pittsburgh, Pennsylvania 15282, United States. \\ ${ }^{d}$ Departamento de Química, Facultad de Ciencias Básicas, Universidad de Antofagasta, \\ Campus Coloso, Antofagasta 1240000, Chile. \\ ${ }^{e}$ Laboratorio de Cristalografía, Departamento de Química, Facultad de Ciencias, \\ Universidad de Los Andes, Mérida 5101, Venezuela. \\ *e-mail: gerzon@ula.ve
}

Received 28 May 2021; accepted 29 August 2021

\begin{abstract}
The quaternary alloy $(\mathrm{CuIn})_{2} \mathrm{NbTe}_{5}$ was synthesized by solid-state reaction using the melt and annealing technique. The thermal analysis shows that this compound melts at $1026 \mathrm{~K}$. The present alloy is isotypic with $\mathrm{Cu}_{2} \mathrm{FeIn}_{2} \mathrm{Se}_{5}$ and crystallizes in the space group $P \overline{4} 2 c\left(\mathrm{~N}^{\circ} 112\right)$, with unit cell parameters $a=6.1964(2) \AA, c=12.4761(4) \AA, c / a=2.01, V=479.02(3) \AA^{3}$. (CuIn) $)_{2} \mathrm{NbTe}_{5}$, belonging to the system $\left(\mathrm{CuInSe}_{2}\right)_{1-x}(\mathrm{FeSe})_{x}$ with $x=1 / 3$, is a new adamantane compound with a $P$-chalcopyrite structure. This structure is characterized by a double alternation of anions-cations layers according to the Te-Te: Nb-In-Nb-In: $\mathrm{Cu}-\mathrm{In}-\mathrm{Cu}$-In: Te-Te sequence, along the 010 direction.
\end{abstract}

Keywords: Chalcogenide; $P$-chalcopyrite; chemical synthesis; thermal analysis; crystal structure.

DOI: https://doi.org/10.31349/RevMexFis.68.010502

\section{Introduction}

Chalcopyrite compounds of the type I-III-VI ${ }_{2}$ (I: Cu, Ag; III: $\mathrm{Al}, \mathrm{Ga}, \mathrm{In}$; VI: S, Se, Te) had been extensively studied due to their applications, particularly in thin-film solar cells [1-2]. However, in the last years, there was a renewed interest in these compounds, and their alloys, due to their possible utilization in thermoelectric conversion [3-7] and spintronic devices [8-10]. Moreover, a superconductor behavior observed in chalcopyrite alloys obtained by cationic substitution with transition metals ( $\mathrm{Nb}$ and $\mathrm{Co}$ ) has increased the attention on these versatile materials [11-12]. On the other hand, transition metal chalcogenides (TMC) based on $\mathrm{Nb}$ and $\mathrm{Ta}$ have caught the attention of the scientist for their topological crystal structure and unusual properties [13]. The latter includes charge density waves (CDW) [14] and superconductivity [1518]. Naturally, part of the interest has focused on (I-III$\mathrm{VI}_{2}$ )/(TM-VI) alloys looking for room temperature ferromagnetism and high-temperature superconduction [11-12,19-22]. It is worth noting here that the origin of superconductivity in TMC (and in their alloys with chalcopyrites) is until now under investigation. From the crystallographic point of view, for TMC, the analysis differs for the bulk, which possesses a global inversion center, and a single monolayer which is non-centrosymmetric. The lack of a definite parity allows for the emergence of unconventional superconducting states. In (I-III- $\left.\mathrm{VI}_{2}\right) /(\mathrm{TM}-\mathrm{VI})$ alloys there is a transition from the bulk form of I-III-VI $\mathrm{VI}_{2}$ to the layered form of TMC; how this transition takes place and when superconducting states appeared, are questions that must be investigated. A big help must be coming from ab initio calculations of the density of states (DOS) which might reveal the presence of flat bands and spikes in the DOS function characteristic of superconducting states.

$\mathrm{CuInTe}_{2}$ is a well-known semiconductor compound that crystallizes in the ordered chalcopyrite structure, space group $I \overline{4} 2 d, \mathrm{Z}=4$, unit cell parameters $a=6.194(2) \AA$ and $c=$ $12.416(4) \AA$ [23], with moderate electrical transport and low thermal conductivity. Additionally, it possesses the better value of the figure of merit zT of 1.18 at $850 \mathrm{~K}$ for an undoped diamond-like material [24].

$\mathrm{NbTe}$ is a transition metal chalcogenide (TMC) that belongs to the $\mathrm{Nb}_{1-x} \mathrm{Te}_{x}$ system with $x=1 / 2$; however, nominally NbTe generally exists as a mixture of $\operatorname{NbTe}_{2}(x=2 / 3)$, $\mathrm{NbTe}_{3}(x=3 / 4)$, and $\mathrm{NbTe}_{4}(x=4 / 5)$ phases [25]. $\mathrm{NbTe}_{2}$ crystallizes in the monoclinic system (s.g. C2/m) with a layer-like structure [26] and can be considered as being made up of varying numbers of "layer molecules" within which the cations have either distorted octahedral or regular trigonal prismatic anion coordination [27]. It has been also reported that it is a superconductor metal with $T_{c} \sim 0.7 \mathrm{~K}$ [28]. $\mathrm{NbTe}_{3}$ is not stable in bulk, however, can be synthesized via nanoconfined growth within the stabilizing cavity of multiwalled carbon nanotubes [29]. $\mathrm{NbTe}_{4}$ crystallizes in a tetragonal structure (s.g $P \overline{4} 2 c$ ) [29] and is a charge-density-wave (CDW) material under ambient pressure. However, with in- 


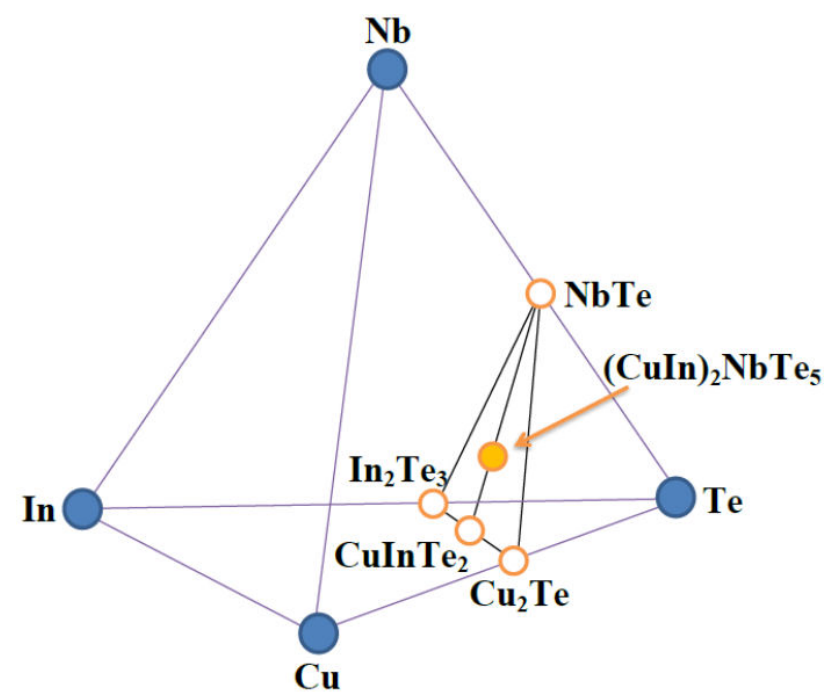

FIgURE 1. Pyramid of compositions for the $\mathrm{Cu}-\mathrm{In}-\mathrm{Nb}-\mathrm{Te}$ quaternary system.

creasing pressure, the CDW transition temperature is gradually suppressed, and superconducting transition, which is fingerprinted by a steep resistivity drop, emerges at pressures above $12.4 \mathrm{GPa}$. Under pressure, $p=69 \mathrm{GPa}$, zero resistance is detected with a transition temperature $T_{C}=2.2 \mathrm{~K}$ [29].

For the alloy CuNbInTe 3 which corresponds to $x=1 / 2$ in the $\left(\mathrm{CuInTe}_{2}\right)_{1-x}(\mathrm{NbTe})_{x}$ system a much higher transition temperature $T_{c}=12 \mathrm{~K}$ has been reported [12], indicative of the interest in the investigation of these new alloys. In this work, we report the synthesis and preliminary characterization of new components of the $\mathrm{Cu}-\mathrm{Nb}-\mathrm{In}-\mathrm{Te}$ quaternary system (Fig. 1). In particular, the synthesis and structural characterization of the new alloy $(\mathrm{CuIn})_{2} \mathrm{NbTe}_{5}$, belonging to the general $\left(\mathrm{CuInTe}_{2}\right)_{1-x}(\mathrm{NbTe})_{x}$ system with $x=1 / 3$, was performed.

\section{Experimental details}

$(\mathrm{CuIn})_{2} \mathrm{NbTe}_{5}$ was prepared by a solid-state reaction from a mixture of the elements Copper, Indium, Niobium, and Tellurium, with nominal purity of 99.99 wt. \% (GoodFellow), and a nominal composition of $\mathrm{Cu}: \mathrm{In}: \mathrm{Nb}: \mathrm{Te}=2: 2: 1: 5$. The mixture was introduced into an evacuated $\left(10^{-4}\right.$ Torr $)$ quartz ampoule, in which the inner walls were previously carbonized to prevent the chemical reaction of the elements with quartz. The quartz ampoule was sealed under vacuum and the fusion procedure was carried out inside a furnace heated up to $1500 \mathrm{~K}$, at $20 \mathrm{~K} / \mathrm{h}$ with a stop of $48 \mathrm{~h}$ at the melting point of Tellurium $(723 \mathrm{~K})$. The complete mixing of all the elements was assured using a shaking mechanical system during all the heating process, which was maintained for others $48 \mathrm{~h}$. Then, the temperature was gradually reduced at the same rate of $20^{\circ} / \mathrm{h}$, down to $900 \mathrm{~K}$. The ampoule was kept at this temperature for 30 days. Finally, the sample was cooled to room temperature at a rate of $10^{\circ} / \mathrm{h}$.
The chemical composition analysis of the sample was examined by scanning electron microscopy technique (SEM), using Hitachi S2500 equipment equipped with a Kevex accessory. The composition was found by an energy-dispersive $\mathrm{x}$-ray spectrometer (EDS) coupled with a computer-based multichannel analyzer. For the EDS analysis, $\mathrm{K}_{\alpha}$ lines were used. A standardless EDS analysis was made with a relative error of $\pm 5-10 \%$ and detection limits of the order of 0.3 wt $\%$, where the k-ratios are based on theoretical standards. Three different regions of the ingot were scanned, and the average atomic percentages were: $\mathrm{Cu}(20.4 \%), \mathrm{In}(19.8 \%), \mathrm{Nb}$ $(9.7 \%)$, and $\mathrm{Te}(50.1 \%)$, which is in good qualitative agreement with the ideal composition 2:2:1:5.

Differential Thermal Analysis (DTA) measurements were obtained in the temperature range between $293 \mathrm{~K}$ and 1423 K, using a Perkin-Elmer DTA-7 with aluminum and gold used as reference materials. The charge of the powdered alloy was approximately $100 \mathrm{mg}$ weight. Both heating and cooling runs were carried out on each sample, the average rates of these runs being approximately $10^{\circ} \mathrm{C} / \mathrm{min}$. The error in determining these temperatures is about $\pm 10 \mathrm{~K}$.

For the powder X-ray diffraction measurement, the synthesized sample was ground in an agate mortar and the resultant powder was dispersed on a zero-background Si sample holder. The X-ray powder diffraction data were collected at room temperature in a $\theta / \theta$ reflection mode using a Siemens D5005 diffractometer. This instrument is equipped with an $\mathrm{X}$-ray tube $\left(\mathrm{CuK}_{\alpha 1}\right.$ radiation: $\left.\lambda=1.54056 \AA ; 40 \mathrm{kV}, 30 \mathrm{~mA}\right)$ and a diffracted beam graphite monochromator. A $1 \mathrm{~mm}$ aperture slit, a $1 \mathrm{~mm}$ divergence slit, a $0.1 \mathrm{~mm}$ monochromator slit, and a $0.6 \mathrm{~mm}$ detector slit were used. The specimen was scanned in the $2 \theta$ range of $10-100^{\circ}$ with a step size of $0.02^{\circ}$ and counting time of $50 \mathrm{~s} / \mathrm{step}$. Quartz was used as an external standard. The instrument analytical software was used to establish the positions of the peaks. For the Rietveld refinement, the whole diffraction data was used.

\section{Results and discussion}

\subsection{Differential thermal analysis}

The DTA heating and cooling curves, for compositions $x=$ $0,1 / 3$ and $1 / 2$, belonging to the $\left(\mathrm{CuInTe}_{2}\right)_{1-x}(\mathrm{NbTe})_{x}$ alloy system is displaying, for comparison, in Figs. 2 and 3, respectively. The values obtained for $\mathrm{CuInTe}_{2}(x=0)$ are in good agreement with those reported previously $[30,31]$. It can be observed in the heating curves that the congruent melting of $\mathrm{CuInTe}_{2}$ decreases in temperature with the composition value $x$ and becomes incongruently. This behavior is indicative that compositions $x=1 / 3$ and $x=1 / 2$ are alloys and not intermediate compounds in the phase diagram. $(\mathrm{CuIn})_{2} \mathrm{NbTe}_{5}$ melts incongruent at $1026 \mathrm{~K}$.

In the cooling cycle is observed the apparition of a new peak at $847 \mathrm{~K}$; this solid-to-solid transition may be associated with cationic disordering, but with the available experimental data the complete determination can be only speculative. 


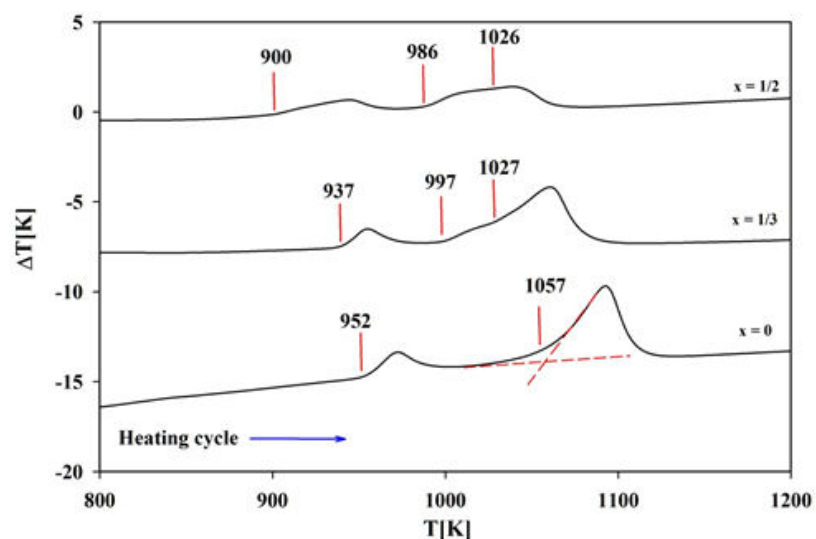

FIGURE 2. DTA heating cycle for the $\left(\mathrm{CuInTe}_{2}\right)_{1-x}(\mathrm{NbTe})_{x}$ alloy system. The dashed red line indicates the accepted criteria (intercept of the baseline with the slope of the peak) for the determination of the thermal transition values (continuous red line and numbers).

\subsection{Crystal structure analysis}

The powder X-ray diffraction pattern of $(\mathrm{CuIn})_{2} \mathrm{NbTe}_{5}$ was indexed using the Dicvol program [32] in the Winplotr suite [33]. A tetragonal cell of dimensions $a=5.780(1) \AA$, $c=11.610(2) \AA$ was obtained. These parameters are similar in magnitude to the parent's chalcopyrite structure $\mathrm{CuInTe}_{2}$ [23]. The systematic absence condition in the general reflections of the type $h k l$ indicates a $P$-type cell, and the $h h l: l=2 \mathrm{n}$ and $00 l: l=2 \mathrm{n}$ conditions suggests the space groups $P \overline{4} 2 c\left(\mathrm{~N}^{\circ} 112\right), P \overline{4} 2 m\left(\mathrm{~N}^{\circ} 105\right)$, and $P \overline{4} 2 / m m c$ $\left(\mathrm{N}^{\circ} 131\right)$. However, studying the chemical composition,

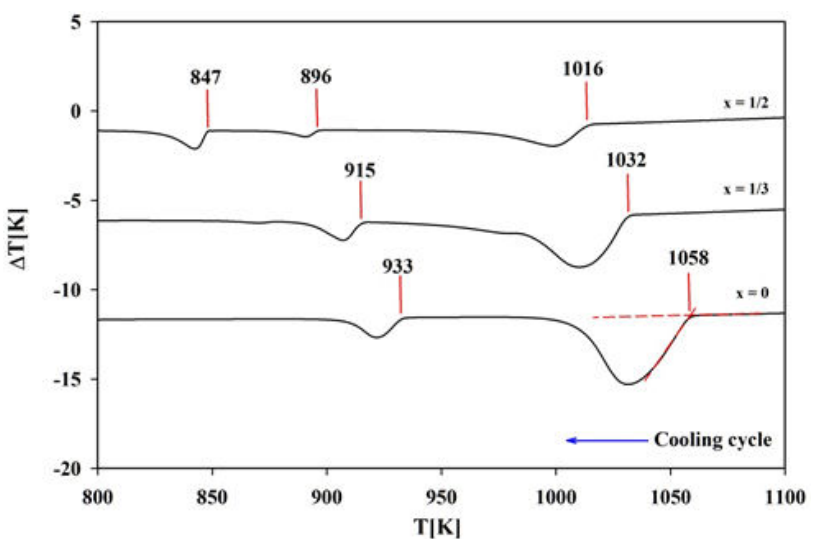

FIGURE 3. DTA cooling cycle for the $\left(\mathrm{CuInTe}_{2}\right)_{1-x}(\mathrm{NbTe})_{x}$ alloy system. The dashed red line indicates the accepted criteria (intercept of the baseline with the slope of the peak) for the determination of the thermal transition values (continuous red line and numbers).

crystal system, and unit cell parameters, this material can be considered as isostructural with the $\mathrm{Cu}_{2} \mathrm{NbIn}_{2} \mathrm{Se}_{5}$ compound, which crystallizes in the tetragonal space group $P \overline{4} 2 c\left(\mathrm{~N}^{\circ}\right.$ 112) [19]. In the cationic distribution when replacing the $\mathrm{Nb}$ and Te atoms for those of $\mathrm{Fe}$ and Se positions all reflections were well indexed in this space group.

The Rietveld refinement analysis was performed using the Fullprof program [35]. The refinement parameters were scale factor, background, unit cell parameters, peak profile, and atomic coordinates. With the powder laboratory diffraction data available it was only possible to describe the thermal motion by one isotropic temperature factor for each type of

TABLE I. Experimental details and Rietveld refinement results for $\mathrm{Cu}_{2} \mathrm{NbIn}_{2} \mathrm{Te}_{5}$.

Data collection
Diffractometer
Mode
Scan method
data range $2 \theta\left(^{\circ}\right)$
Crystal Data
Chemical Formula
Crystal system
$d_{\text {calc }}\left(\mathrm{g} / \mathrm{cm}^{-3}\right)$
$a(\AA)$
$c(\AA)$

Refinement

step intensities

$\mathrm{R}_{\exp }(\%)$

$\mathrm{R}_{p}(\%)$

$\mathrm{S}$

Siemens D5005
Reflection
Step
$10-100$

$(\mathrm{CuIn})_{2} \mathrm{NbTe}_{5}$

tetragonal

7.45

$6.1964(2)$

12.4761(4)

4501

7.0

7.7

1.2

$\begin{array}{cc}\text { Temperature }(\mathrm{K}) & 298(1) \\ \text { wavelength }\left(\mathrm{CuK}_{\alpha}\right) & 1.54056 \AA \\ \text { step size } 2 \theta\left(^{\circ}\right) & 0.02 \\ \text { counting time (s) } & 40\end{array}$

Formula Weight (g/mol)

807.38

Space group

$\mathrm{Z}$

$P \overline{4} 2 c\left(\mathrm{~N}^{\circ} 112\right)$

$\mathrm{c} / \mathrm{a}$

$1.6(8 / 5)$

2.01

479.02(3)

independent reflections $\quad 152$

$\begin{array}{cc}\mathrm{R}_{w p}(\%) & 8.1 \\ \mathrm{R}_{B}(\%) & 7.5\end{array}$

$\mathrm{R}_{\exp }=100\left[(\mathrm{~N}-\mathrm{P}+\mathrm{C}) / \sum_{w}\left(y_{o b s}^{2}\right)\right]^{1 / 2} ; \mathbf{R}_{p}=100 \sum\left|y_{\mathrm{obs}}-y_{\text {calc }}\right| / \sum\left|y_{\mathrm{obs}}\right| ; \mathbf{R}_{w p}=100\left[\sum_{w}\left|y_{\mathrm{obs}}-y_{\text {calc }}\right|^{2} / \sum_{w}\left|y_{\mathrm{obs}}\right|^{2}\right]^{1 / 2} ; \mathrm{S}=\left[R_{w p} / R_{\exp }\right] ;$ $\mathrm{R}_{B}=100 \sum_{k}\left|I_{k}-I_{c k}\right| / \sum_{k}\left|I_{k}\right| ; \mathrm{N}-\mathrm{P}+\mathrm{C}$ is the number of degrees of freedom. 
TABLE II. Atomic coordinates, Wyckoff position, occupancy factors, isotropic temperature factors, bond, and angle distances for (CuIn) ${ }_{2} \mathrm{Nb}$ $\mathrm{Te}_{5}$, derived from the Rietveld refinement, and Bond Valence Sum (BVS) calculations.

\begin{tabular}{|c|c|c|c|c|c|c|c|c|}
\hline Atom & Ox. & BVS & Wyck. & $x$ & $y$ & $z$ & foc & $\mathrm{B}\left(\AA^{2}\right)$ \\
\hline $\mathrm{Cu} 1$ & +1 & 1.4 & $2 e$ & 0 & 0 & 0 & 1 & $0.6(1)$ \\
\hline $\mathrm{Nb}$ & +2 & 2.3 & $2 d$ & 0 & $1 / 2$ & $1 / 4$ & 0.8 & $0.5(1)$ \\
\hline $\mathrm{Cu} 2$ & +1 & & $2 d$ & 0 & $1 / 2$ & $1 / 4$ & 0.1 & $0.6(1)$ \\
\hline In 2 & +3 & & $2 d$ & 0 & $1 / 2$ & $1 / 4$ & 0.1 & $0.9(1)$ \\
\hline In 1 & +3 & 3.1 & $2 b$ & $1 / 2$ & 0 & $1 / 4$ & 1 & $0.9(1)$ \\
\hline $\mathrm{Cu} 3$ & +1 & & $2 f$ & $1 / 2$ & $1 / 2$ & 0 & 0.5 & $0.6(1)$ \\
\hline In 3 & +3 & & $2 f$ & $1 / 2$ & $1 / 2$ & 0 & 0.5 & $0.9(1)$ \\
\hline $\mathrm{Te}$ & -2 & 2.2 & $8 n$ & $0.2516(7)$ & $0.2558(7)$ & $0.1187(5)$ & 1 & $1.2(1)$ \\
\hline $\mathrm{Cu} 1-\mathrm{Te}$ & \multicolumn{2}{|c|}{$2.671(2)$} & \multicolumn{2}{|c|}{ In $1-\mathrm{Te}^{\mathrm{i}}$} & $2.750(2)$ & $\mathrm{Nb}-\mathrm{Te}$ & \multicolumn{2}{|c|}{$2.721(2)$} \\
\hline $\mathrm{Te}^{\mathrm{ii}}-\mathrm{Cu} 1-\mathrm{Te}$ & \multicolumn{2}{|c|}{$107.90(5)$} & \multicolumn{2}{|c|}{$\mathrm{Te}^{i i}-\mathrm{Cu} 1-\mathrm{Te}^{\mathrm{iii}}$} & $112.66(4)$ & $\mathrm{Te}^{\mathrm{viii}}-\mathrm{Cu} 2-\mathrm{Te}$ & \multicolumn{2}{|c|}{$108.67(5)$} \\
\hline $\mathrm{Te}^{\mathrm{vi}}-\mathrm{In} 1-\mathrm{Te}^{\mathrm{i}}$ & \multicolumn{2}{|c|}{$109.62(5)$} & \multicolumn{2}{|c|}{$\mathrm{Te}^{\mathrm{vi}}-\mathrm{In} 1-\mathrm{Te}^{\mathrm{vii}}$} & $106.89(4)$ & $\mathrm{Te}^{\mathrm{vi}}-\mathrm{In} 1-\mathrm{Te}$ & \multicolumn{2}{|c|}{$111.94(5)$} \\
\hline $\mathrm{Te}-\mathrm{Nb}-\mathrm{Te}^{\mathrm{iv}}$ & \multicolumn{2}{|c|}{$110.09(5)$} & \multicolumn{2}{|c|}{$\mathrm{Te}-\mathrm{Nb}-\mathrm{Te}^{\mathrm{v}}$} & $105.97(4)$ & $\mathrm{Te}^{\mathrm{viii}}-\mathrm{Cu} 2-\mathrm{Te}^{\mathrm{ix}}$ & \multicolumn{2}{|c|}{$111.09(4)$} \\
\hline
\end{tabular}

Symmetry codes: (i) 1-x, -y, z; (ii) -y, x, -z; (iii) y, -x, -z; (iv) x, 1-y, 0.5-z; (v) -x, 1-y, z; (vi) x, -y, 0.5-z; (vii) 1-x, y, 0.5-z; (viii) y, 1-x, -z; (ix) 1-y, x, -z. $V_{i}=\sum_{j} \exp \left[\left(R_{o}-R_{i j}\right) / b\right] ; \mathrm{b}=0.37 \AA ; \operatorname{ro}(\mathrm{Cu}-\mathrm{Te})=2.27 \AA, \operatorname{ro}(\mathrm{In}-\mathrm{Te})=2.69 \AA, r_{o}(\mathrm{Nb}-\mathrm{Te})=2.60 \AA$.

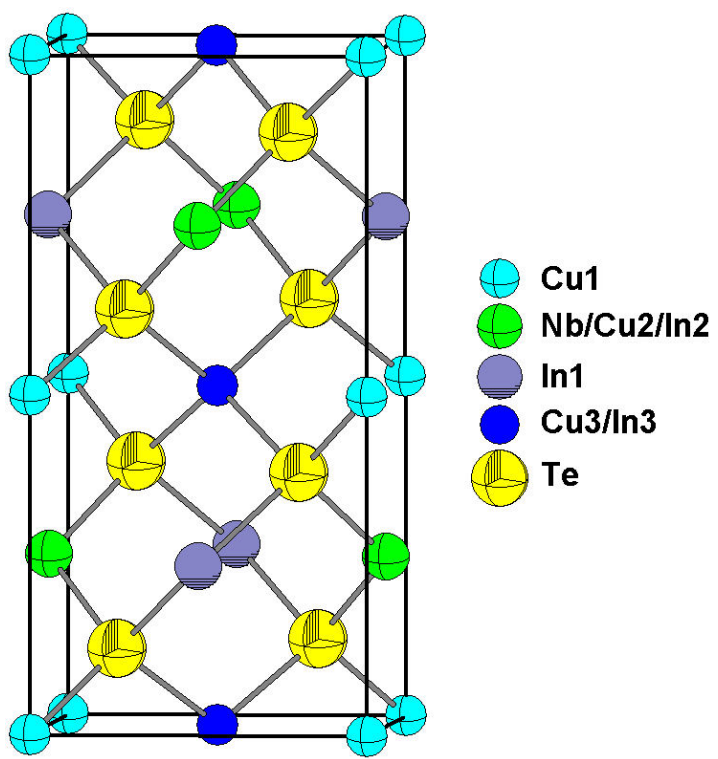

FIGURE 4. Unit cell diagram of the new alloy $(\mathrm{CuIn})_{2} \mathrm{NbTe}_{5}$ in the space group $P \overline{4} 2 c$.

atom. The angular dependence was described using the Cagliotti formula [36], and the peak shapes were described by the Thompson-Cox-Hastings pseudo-Voigt profile function [37]. Details of the crystal data collection and structure refinement are summarized in Table I. Table II show the crystallographic information obtained from the final adjustment. The Rietveld refinement plot is displayed in Fig. 3.

The crystal structure of (CuIn) ${ }_{2} \mathrm{NbTe}_{5}$ is shown in Fig. 4. This corresponds to a normal adamantane structure [38] with a $P$-chalcopyrite structure [39], which consists of a threedimensional arrangement of distorted $\mathrm{CuTe}_{4}, \mathrm{InTe}_{4}$, and $\mathrm{NbTe}_{4}$ tetrahedral. This array is expected for adamantane compounds [38] and is characterized by the tetrahedral coordination of both cations and anions. Figure 5 shows a projection of the tetrahedral packing of $(\mathrm{CuIn})_{2} \mathrm{NbTe}_{5}$ along the ca plane. It is possible to observe that the structure is characterized by a double alternation of tellurium-cations layers along the 010 direction according to the sequence: Te-Te : $\mathrm{Nb}-\mathrm{In}-\mathrm{Nb}-\mathrm{In}$ : Cu-In-Cu-In : Te-Te.

To check the refined crystal structure model, empirical Bond Valence Sum (BVS) was calculated. This method allows to analyze interatomic distances using the BVS formula $\left(V_{i}=\sum_{j} \exp \left[\left(R_{o}-R_{i j}\right) / b\right]\right)$, based on the bondstrength examination [40,41]. Table II shows the BVS results for $(\mathrm{CuIn})_{2} \mathrm{NbTe}_{5}$ and is possible to observe as the expected charges of the ions match the obtained BVS values: $\left(\mathrm{Cu}^{+}\right)=$ $1.4,\left(\mathrm{In}^{3+}\right)=3.1,\left(\mathrm{Nb}^{2+}\right)=2.3,\left(\mathrm{Te}^{2-}\right)=2.2$.

Interatomic distances are shorter than the sum of the ionic radii for $r \mathrm{Cu}^{1+}=0.6, r \mathrm{In}^{3+}=0.62, r \mathrm{Te}^{2-}=2.21$ [42],

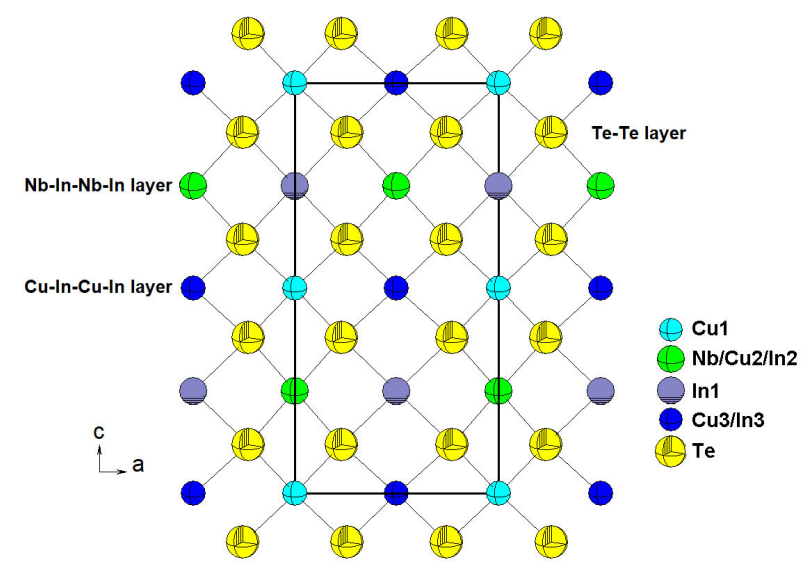

FIGURE 5. Projection of the tetrahedral packing of (CuIn $)_{2} \mathrm{NbTe}_{5}$ along the ca plane. 
and $r \mathrm{Nb}^{2+}=0.73$ [43]. Bond distances in Table II show a Cu-Te bond length of 2.639(1) $\AA$, In-Te of 2.768(1) $\AA$ and $\mathrm{Nb}-\mathrm{Te}$ of $2.756(1) \AA$. These lengths compare well to those found for the related ternary adamantane structures: $\mathrm{CuInTe}_{2}$ [23], CuNbTe 2 [44], $\mathrm{Cu}_{3} \mathrm{NbTe}_{4}$ [45], $\mathrm{AgIn}_{5} \mathrm{Te}_{8}$ [46], AgInTe 2 [47], $\mathrm{Cu}_{3} \mathrm{In}_{5} \mathrm{Te}_{9}$ [48], $\mathrm{Cu}_{3} \mathrm{In}_{7} \mathrm{Te}_{12}$ [49], and the quaternaries: $\mathrm{CuTa}_{2} \mathrm{InTe}_{4}$ [50], $\mathrm{CuCo}_{2} \mathrm{InTe}_{4}$ and $\mathrm{CuNi}_{2} \mathrm{InTe}_{4}$ [51], and CuFeInTe 3 [52].

\section{Conclusions}

The quaternary alloy $(\mathrm{CuIn})_{2} \mathrm{NbTe}_{5}$ was prepared by the melting and annealing method and its crystal structure refined using powder X-ray diffraction data. This compound is isotypic with $\mathrm{Cu}_{2} \mathrm{FeIn}_{2} \mathrm{Se}_{5}$ and crystallizes through a $P$-chalcopyrite fashion in a normal adamantane structure with tetrahedral coordination around cations and anions. The structure is characterized by a double alternation of anioncation layers. The chemical structure was checked by analysis of the interatomic distances using the Bond Valence Sum (BVS) formula based on bond-strength examination. The new quaternary alloy melts incongruent at $1026 \mathrm{~K}$.

\section{Acknowledgments}

This work was partially done into G. E. Delgado visit at the Universidad de Antofagasta, supported by MINEDUC-UA project, code ANT 1856.

Authors thank to Agencia Nacional de Investigación y Desarrollo (ANID-Chile) for the financial support for this research (Grant No. 3190500).
1. S. Siebentritt, Chalcopyrite compound semiconductors for thin-film solar cells, Curr. Opin. Green Sustainable Chem. 4 (2017) 1. htt://dx.doi.org/10.1016/j.cogsc. 2017.02 .001

2. G. Regmi et al., Perspectives of chalcopyrite-based CIGSe thin-film solar cell: a review, J Mater. Sci-Mater. Electron. 31 (2020) 7286, htts://doi.org/10.1007/ s10854-020-03338-2

3. J. Yang, Q. Fan, and X. Cheng, Prediction for electronic, vibrational, and thermoelectric properties of chalcopyrite $\mathrm{AgX}(\mathrm{X}=\mathrm{In}, \mathrm{Ga}) \mathrm{Te}_{2}$ : PBE+U approach, R. Soc. Open Sci. 4 (2017) 170750, htt://dx.doi.org/10.1098/rsos. 170750 .

4. H. Ahmoum et al., Electronic and thermoelectric properties of chalcopyrite compounds $\mathrm{Cu} 2(\mathrm{XY}) \mathrm{S} 4(\mathrm{X}=\mathrm{Zn}, \mathrm{Cd}$, and $\mathrm{Y}=\mathrm{Sn}$, $\mathrm{Pb}$ ): a first-principles study, Indian J. Phys. 95 (2021) 281, htts://doi.org/10.1007/s12648-020-01698-3

5. C. Wang et al., Tetrahedral distortion and thermoelectric performance of the Ag-substituted CuInTe2 chalcopyrite compound, ACS Appl. Energy Mater. 3 (2020) 11015, htts://doi. org/10.1021/acsaem.0c01867

6. M. Singh et al., Chalcopyrite nanoparticles as a sustainable thermoelectric material. Nanomaterials 5 (2015) 1820. htts : //doi.org/10.3390/nano5041820

7. S. Mukherjee et al., Tuning the thermoelectric properties of chalcopyrite by $\mathrm{Co}$ and Se double substitution, AIP Conf. Proc. 2115 (2019) 030574, htts://doi.org/10.1063/ 1.5113413 .

8. W. Feng, D. Xiao, J. Ding, and Y. Yao, Three-dimensional topological insulators in I-III-VI2 and II-IV-V2 chalcopyrite semiconductors. Phys Rev. Lett. 106 (2011) 016402. htts: //doi.org/10.1103/PhysRevLett.106.016402.

9. Z. Zhuolei, X. Beibei, Z. Lin, and R. Shenqiang, Hybrid chalcopyrite-polymer magnetoconducting materials, ACS Appl. Mater. Interfaces 8 (2016) 11215, htts://doi.org/10. 1021 /acsami.6b03362
10. X. Li and J. Yang, First-principles design of spintronics materials, Natl. Sci. Rev. 3 (2016) 365, htts://doi .org/10. $1093 / \mathrm{nsr} / \mathrm{nww} 026$

11. P. Grima-Gallardo, G. E. Delgado, E. Pérez-Cappé, J. A. Aitken, and D. Prakash Rai. Synthesis, X-ray diffraction, and magnetic measurements of $\mathrm{Cu}(\mathrm{Ni}, \mathrm{Co}) 2 \mathrm{InS} 4$ alloys: superconductor behavior of $\mathrm{CuCo}_{2} \mathrm{InS}_{4}$, Rev. LatinAm. Metal. Mat. 40 (2020) 131.

12. P. Grima-Gallardo et al., Superconductivity observation in a (CuInTe2)1-x(NbTe)x alloy with $x=0.5$, Adv. Mat. Sci. Technol. 7 (2013) 1.

13. X. Yang et al., Pressure-induced superconductivity bordering a charge-density-wave state in $\mathrm{NbTe} 4$ with strong spin-orbit coupling, Sci. Rep. 8 (2018) 6298, htts://doi:10.1038/ s41598-018-24572-z

14. D. E. Moncton, J. D. Axe, and F. J. DiSalvo, Neutron scattering study of the charge-density-wave transitions in $2 \mathrm{H}-\mathrm{TaSe}_{2}$ and 2H-NbSe ${ }_{2}$, Phys. Rev. B 16 (1977) 801, htts: / / doi.org/ 10.1103/PhysRevB.16.801

15. R. C. Morris, R. V. Coleman, and R. Bhandari, Superconductivity and magnetoresistance in $\mathrm{NbSe}_{2}$, Phys. Rev. B 5 (1972) 895.htts://doi.org/10.1103/PhysRevB.5.895

16. F. R. Gamble, F. J. DiSalvo, R. A. Klemm, and T. H. Geballe, Superconductivity in layered structure organometallic crystals, Science 168 (1970) 568, htts://doi.org/10.1126/ science.168.3931.568

17. X. C. Pan et al., Pressure-driven dome-shaped superconductivity and electronic structural evolution in tungsten ditelluride. Nat. Commun. 6 (2015) 7805, htts://doi.org/ $10.1038 /$ ncomms 8805

18. D. Kang et al., Superconductivity emerging from a suppressed large magnetoresistant state in tungsten ditelluride, Nat. Commun. 6 (2015) 7804. htts://doi.org/10.1038/ ncomms 8804

19. G. E. Delgado, P. Grima-Gallardo, J. A. Aitken, A. Cárdenas, and I. Brito, The new P-chalcopyrite compound Cu2FeIn2Se5; 
synthesis, thermal analysis (DTA), and crystal structure analysis by X-ray powder diffraction (XRPD), Rev. Mex. Fís. 67 (2021) 18, htts://doi.org/10.31349/RevMexFis. 67.18

20. P. Grima-Gallardo, S. Durán, M. Muñoz, D. P. Rai, and G. E. Delgado, $\left(\mathrm{Cu}_{0.4} \mathrm{Al}_{0.3}\right) \mathrm{TaSe}_{2}$ : Preparation and crystal structure analysis from X-ray powder diffraction, South. Braz. J. of Chem. 28 (2020) 1, htt://www.deboni.he.com.br/sbjchem/ jornal/2020v2/01_DELGADO_pgs_01_06.pdf

21. P. Grima-Gallardo et al., $\left(\mathrm{CuAlSe}_{2}\right)_{1-x}(\mathrm{TaSe})_{x}$ alloy system $(0 \leq x \leq 0.5)$ : X-ray diffraction, differential thermal analysis and scanning electron microscopy measurements, Rev. LatinAm. Metal. Mat. 41 (2021) 34, htt://www.rlmm.org/ ojs/index.php/rlmm/article/view/1071

22. P. Grima-Gallardo et al., X-ray diffraction, scanning electron microscopy and differential thermal analysis of $(\mathrm{CuGaSe} 2)_{1-x}$ $(\mathrm{TaSe})_{x}$ alloys system $(0 \leq x \leq 0.5)$. Senhri J. Multidiscip. Stud. 5 (2020) 1. htts://doi.org/10.36110/s jms. 2020.05 .01 .001

23. K. S. Knight, The crystal structures of $\mathrm{CuInSe}_{2}$ and $\mathrm{CuInTe}_{2}$, Mater. Res. Bull. 27 (1992) 161. htts://doi.org/10. 1016/0025-5408(92)90209-I

24. R. Liu et al., Ternary compound CuInTe2: a promising thermoelectric material with diamond-like structure. Chem. Commun. 48 (2012) 3818, htts://doi.org/10.1039/ C2CC30318C

25. S. Altaf et al., Comparative study of selenides and tellurides of transition metals ( $\mathrm{Nb}$ and $\mathrm{Ta}$ ) with respect to its catalytic, antimicrobial, and molecular docking performance, Nanoscale Res. Lett. 15 (2020) 144. htts://doi.org/10.1186/ s11671-020-03375-0

26. B. E. Brown, The crystal structures of $\mathrm{NbTe}_{2}$ and $\mathrm{TaTe}_{2}$, Acta Cryst. 20 (1966) 264, htts://doi.org/10.1107/ S0365110X66000501

27. E. Revolinsky, B. E. Brown, D. J. Beerntsen, and C. H. Armitage, The selenide and telluride systems of niobium and tantalum, J. Less-Common Met. 8 (1965) 63. htt s://doi. org/10.1016/0022-5088(65)90058-5

28. S. Nagata, T. Abe, S. Ebisu, Y. Ishihara, and K. Tsutsumi, Superconductivity in the metallic layered compound $\mathrm{NbTe} 2 . J$. Phys. Chem. Solids 54 (1993) 895. htts ://doi.org/10. 1016/0022-3697(93) 90215-D

29. S. Stonemeyer et al., Stabilization of $\mathrm{NbTe}_{3}, \mathrm{VTe}_{3}$, and $\mathrm{TiTe}_{3}$ via nanotube encapsulation. J. Am. Chem. Soc. 143 (2021) 4563, htts://doi:10.1021/jacs.0c10175

30. X. Yang et al., Pressure-induced superconductivity bordering a charge-density-wave state in $\mathrm{NbTe} 4$ with strong spin-orbit coupling, Sci. Rep. 8 (2018) 6298, htt s://doi:10.1038/ s41598-018-24572-z

31. E. Guerrero, M. Quintero, M. Delgado, and J.C. Woolley. T (z) Diagram and optical energy gap values of $\mathrm{Cd}_{1-z} \mathrm{Mn}_{z} \mathrm{In}_{2} \mathrm{Te}_{4}$ alloys, Phys. Stat. Sol. A 129 (1992) K83, htts://doi.org/ $10.1002 / \mathrm{pssa} .2211290231$

32. I. V. Bodnar, I. A. Viktorov, and I. A. Zabelina, Synthesis of $\mathrm{CuGa}_{x} \mathrm{In}_{1-x} \mathrm{Te}_{2}$ solid solutions and their physicochemical properties, Russ. J. Inorg. Chem. 38 (1993) 809. htt: //pascal-francis.inist.fr/vibad/index. php?action=getRecordDetail\&idt $=4770613$

33. A. Boultif and D. Louër, Powder pattern indexing with the dichotomy method, J. Appl. Cryst. 37 (2004) 724, htts: //doi.org/10.1107/S0021889804014876

34. T. Roisnel and J. Rodríguez-Carvajal, WinPLOTR: a Windows tool for powder diffraction patterns analysis, Mater. Sci. For. 378-381 (2001) 118, htts://doi.org/10.4028/www. scientific.net/MSF.378-381.118

35. H. M. Rietveld, A profile refinement method for nuclear and magnetic structures, J. Appl. Cryst. 2 (1969) 65, htts:// doi.org/10.1107/S0021889869006558

36. J. Rodríguez-Carvajal, Recent advances in magnetic structure determination by neutron powder diffraction, Phys. B 192 (1993) 55, htts://doi.org/10.1016/ 0921-4526(93) 90108-I

37. G. Caglioti, A. Paoletti, and F. P. Ricci, Choice of collimators for a crystal spectrometer for neutron diffraction, Nucl. Instrum. 3 (1958) 223, htts://doi.org/10.1016/ 0369-643X(58) 90029-X.

38. P. Thompson, D. E. Cox, and J. B. Hastings, Rietveld refinement of Debye-Scherrer synchrotron X-ray data from Al2O3, J. Appl. Cryst. 20 (1987) 79, htts: //doi.org/10.1107/ S0021889887087090

39. E. Parthé, Wurtzite and Sphalerite Structures, in Intermetallic Compounds, edited by J. H. Westbrook and R. L. Fleischer, Vol. 1 (John Wiley and Sons, Chichester, 1995).

40. W. Hönle, G. Kühn, and U.-C. Boehnke, Crystal structures of two quenched Cu-In-Se phases, Cryst. Res. Technol. 23 (1988) 1347, htts://doi.org/10.1002/crat. 2170231027

41. I. D. Brown and D. Altermatt, Bond-valence parameters obtained from a systematic analysis of the Inorganic Crystal Structure Database, Acta Cryst. B 41 (1985) 244, htts:// doi.org/10.1107/S0108768185002063

42. N. E. Brese and M. O'Keeffe, Bond-valence parameters for solids, Acta Cryst. B 47 (1991) 192, htts : / / doi.org/10. $1107 / \mathrm{S} 0108768190011041$

43. R. D. Shannon, Revised effective ionic radii and systematic studies of interatomic distances in halides and chalcogenides, Acta Cryst. A 32 (1976) 751, htts://doi.org/ $10.1107 / \mathrm{S} 0567739476001551$

44. J. Zio'lkowski, New relation between Ionic Radii, Bond Length, and Bond Strength, J. Solid State Chem. 57 (1985) 269, htts://doi.org/10.1016/0022-4596(85) 90152-5

45. T. Sörgel and M. Jansen, Structure refinement, physical properties and electronic structure of new electrochemically copper intercalated group $\mathrm{Vb}$ ditellurides $\mathrm{Cu}_{x} \mathrm{MTe}_{2}(\mathrm{M}=\mathrm{V}, \mathrm{Nb}$, Ta), Solid State Sci. 6 (2004) 1259, htts : / / doi . org/10 . $1016 / j . s o l i d s t a t e s c i e n c e s .2004 .07 .017$

46. G. E. Delgado et al., Synthesis and characterization of the ternary chalcogenide compound $\mathrm{Cu}_{3} \mathrm{NbTe}_{4}$, Chalcogenide Lett. 6 (2009) 335, htt s: / / chalcogen.ro/335. Delgado.pdf 
47. A. J, Mora, G. E. Delgado, C. Pineda, and T. Tinoco, Synthesis and structural study of the AgIn5Te8 compound by Xray powder diffraction, Phys. Stat. Sol. (a) 201 (2004) 1477. htts://doi.org/10.1002/pssa.200406805

48. G. E. Delgado, A. J. Mora, C. Pineda, R. Avila-Godoy, S. Paredes-Dugarte, X-ray powder diffraction data and Rietveld refinement of the ternary semiconductor chalcogenides $\mathrm{AgInSe}_{2}$ and AgInTe ${ }_{2}$, Rev. LatinoAm. Met. Mater. 35 (2015) 110. htt://www.rlmm.org/ojs/index.php/rlmm/ article/view/546

49. G. E. Delgado, C. Rincón, and G. Marroquin, On the crystal structure of the ordered vacancy compound $\mathrm{Cu}_{3} \mathrm{In}_{5} \mathrm{Te}_{9}$, Rev. Mex. Fis. 65 (2019) 360, htts://doi.org/10.31349/ RevMexFis.65.360

50. G. E. Delgado, E. Guedez, G. Sánchez-Pérez, C. Rincón, and G. Marroquin, Evidence of a new ordered va- cancy crystal structure in the compound $\mathrm{Cu}_{3} \mathrm{In}_{7} \mathrm{Te}_{12}, M a$ teria 24 (2019) e12329. htts://doi.org/10.1590/ s1517-707620190001.0643

51. G. E. Delgado et al., Crystal structure of the quaternary compound $\mathrm{CuTa}_{2} \mathrm{InTe}_{4}$ from X-ray powder diffraction. Physica B 403 (2008) 3228. htts://doi.org/10.1016/j. physb.2008.04.022

52. G. E. Delgado et al., Structural characterization of two new quaternary chalcogenides: $\mathrm{CuCo}_{2} \mathrm{InTe}_{4}$ and $\mathrm{CuNi}_{2} \mathrm{InTe}_{4}$, Mater. Res. 19 (2016) 1423. htts: / / doi.org/10.1590/ 1980-5373-mr-2016-0098

53. G. E. Delgado et al., Crystal structure and powder Xray diffraction data of the super-paramagnetic compound $\mathrm{CuFeInTe}_{3}$ 4, Rev. Mex. Fis. 67 (2021) 305. htts://doi. org/10.31349/RevMexFis.67.305 